\title{
Current and future approaches to screening for endometrial cancer
}

Gentry-Maharaj, $\mathrm{A} \mathrm{PhD}^{1 *}$ and Karpinskyj, $\mathrm{C} \mathrm{MSc}^{1}$

${ }^{1}$ MRC Clinical Trials Unit at UCL, Institute of Clinical Trials and Methodology, University College London, United Kingdom

*Corresponding author:

Dr Aleksandra Gentry-Maharaj PhD

MRC Clinical Trials Unit at UCL, Institute of Clinical Trials and Methodology, University College London, United Kingdom

Tel: ++44 2076704887

Email: a.gentry-maharaj@ucl.ac.uk 


\section{ABSTRACT}

Due largely to the rise in obesity and prolonged life expectancy, endometrial cancer rates have increased by $56 \%$ since the early 90 s. Women at high risk (Lynch Syndrome) have a 12 $47 \%$ lifetime risk of developing endometrial cancer and professional societies recommend annual surveillance using transvaginal ultrasound (TVS) and endometrial biopsy (outpatients hysteroscopy) from age 30-35 with hysterectomy from age 40. In women at low risk, screening is not currently advocated. The emerging data from Genome Wide Association studies in combination with epidemiological data may refine risk stratification in the future. In addition to screening, preventative approaches such as intrauterine progesterone may help reduce disease burden in those identified at 'higher risk'.

Keywords: endometrial cancer, endometrial neoplasm, risk factors, risk prediction, screening, transvaginal ultrasound, endometrial sampling, biomarkers, Lynch Syndrome 


\section{Background}

Endometrial cancer (EC) is the most common gynaecological cancer in high-income countries and the fourth most common cancer in women. Worldwide there are over 320,000 cases of EC each year ${ }^{1}$. It is estimated that $3 \%$ of women will develop EC in their lifetime. There has been a sharp rise in incidence with a 56\% increase since the early 90s (1993-2015) ${ }^{2}$. During the last decade alone, the rates of uterine cancer have increased by $21 \%^{2}$. This increase in incidence between the early 1990s and 2010s has largely been attributable to increased rates of obesity, with longer life expectancy also playing a role. US projections for the coming decades predict a $40-50 \%$ rise in incidence to $2030^{3,4}$ which are in part reflected in UK data with reports which suggest an overall increase in incidence from 21 to 33 ASR (age standardised rate), although this is projected to fall by $2035^{5}$. Although typically a disease of high-income countries, increase in incidence has more recently been observed in low-middle income countries (LMIC) such as South Africa, Thailand and Brazil ${ }^{1,6}$. In parallel to this, over the past two decades mortality has also increased, with rates now similar to what they were in the early 80s (age standardised mortality rates decreasing to 5.0 in 1999 and rising to 7.1 in 2016$)^{2}$. There is evidence that this increase is mainly in women over 70 , pertinent to the aging population ${ }^{7}$.

EC is overwhelmingly a disease of postmenopausal women, with over $90 \%$ occurring in women over $50^{8}$, however increasing rates of obesity may lead to a rise in the proportion of pre-menopausal cases ${ }^{9}$. 
As with ovarian cancer, EC has been dichotomously split into Type I and Type II tumours. Type I are almost exclusively endometrioid tumours which are associated with oestrogen exposure. They account for $80-90 \%$ of cases but only $40 \%$ of the deaths ${ }^{10}$. Type II tumours mostly include serous and clear cell cancers which have a high fatality ratio. To have a bigger impact on mortality, preventative and early detection strategies should focus on detecting Type II cancers in parallel with efforts in detecting those that are fatal, whether Type I or Type II. More recent data suggests that four distinct molecular subtypes of EC exist, MMR deficient (MMR-D, deficient for MSH6 and PMS2), POLE exonuclease domain mutated (POLE EDM), p53 wild-type and p53 abnormal (null or missense mutations in p53) ${ }^{11}$.

Three quarters of cases are diagnosed at an early stage (I/II), in which 5- and 10-year survival rates are $95 \%$ and $77 \%$ respectively ${ }^{12}$, the highest of all gynaecological cancers. When diagnosed at late stage (IV), the survival is poor with only $14 \%$ of women surviving for 5 years $^{12}$. The high proportion of ECs diagnosed at an early stage is largely due to abnormal vaginal bleeding being present in $94 \%$ of the cases $^{13}$. In postmenopausal women, the presence of abnormal bleeding (postmenopausal bleeding, $\mathrm{PMB}$ ) equates to a risk of EC of 9\%. In contrast, the risk of EC in pre-menopausal women with abnormal bleeding is only $0.33 \%$ $(95 \% \mathrm{Cl} 0.23-0.48 \%)^{13}$. An EC study comparing 190 symptomatic with 123 asymptomatic women found that asymptomatic women were on average younger, less overweight, more likely to have hypertension ${ }^{14}$ and were less likely to be diagnosed with late stage disease. Asymptomatic women had no prognostic advantage over the symptomatic women, as long as the bleeding had occurred for fewer than 8 weeks ${ }^{14}$. 
The precursor lesion for Type I EC, atypical endometrial hyperplasia (AEH) (referred to in the US as Endometrial Intraepithelial Neoplasia, EIN) most commonly presents with abnormal vaginal bleeding and shares the same oestrogen-exposure related risk factors as EC. Around a third of those with biopsy-diagnosed AEH have concurrent EC at hysterectomy and around $40 \%$ of women with $\mathrm{AEH}$ will progress to $\mathrm{EC}^{15}$. It is therefore important that any screening strategy for EC includes $\mathrm{AEH}$ as a screen positive result.

The identification of risk factors and biomarkers which could be used for risk stratification and early detection strategies in the future is of particular significance in view of the rise in EC incidence and mortality. The epidemiological, reproductive and genetic factors and the current screening strategies for EC are discussed below.

\section{Modifiable risk factors and potential for intervention}

The lifetime risk of developing endometrial cancer is $3 \%$, or 1 in $36^{16}$. As with most cancers, older age is the main risk factor for EC. The most significant risk factor is exposure to endogenous and exogenous unopposed oestrogens, which cause proliferative changes in the endometrium ${ }^{17}$. The hormonal exposure during a woman's life provided by excess adipose tissue is most relevant source in today's society, however reproductive choices also play a key role.

\section{Epidemiological and lifestyle factors}

\section{Obesity}


Thirty to forty percent of EC cases are attributable to obesity, making it the biggest risk factor for the disease ${ }^{18}$. This is due to the estrogenic effects of adipose tissue which causes proliferation of the endometrium. There is some evidence to suggest that obesity is more strongly associated with Type I cancers, which would correlate with the estrogenic aetiology of these tumours ${ }^{10}$. A dose-response relationship between obesity and EC exists, with an $81 \%$ increase in risk per 5-unit increase of BMI during adulthood ${ }^{19}$. When compared to those with 'normal' BMI (18.5-24.9 kg/m²), those who are 'overweight' $\left(25.0-29.9 \mathrm{~kg} / \mathrm{m}^{2}\right)$ are at a 1.43 $(95 \% \mathrm{Cl} 1.30-1.56)$ times increased risk of EC, which rises to 3.33 for those categorised as 'obese' $\left(>30 \mathrm{~kg} / \mathrm{m}^{2}\right)^{20}$.

Women who were previously obese and have lost weight have been shown to experience a risk reduction of EC, making obesity a potentially modifiable risk factor ${ }^{21}$. In comparison to controls, obese women who underwent bariatric surgery and were followed up for 24 years had a 78\% reduction in cancer risk ${ }^{22}$. A 2015 systematic review based on 890,110 women demonstrated a risk reduction in EC of $60 \%{ }^{23}$. In a more recent study of 72 women who underwent bariatric surgery and achieved weight loss at 12 months, following the surgery 5 of 6 women with AEH appeared to undergo regression ( 3 with surgery alone; 2 with intrauterine progestin) $)^{24}$. More data are needed to confirm these findings.

\section{Endogenous hormones}

Whilst older age at menarche $(\mathrm{RR}=0.68,95 \% \mathrm{Cl} 0.58-0.81$ oldest versus youngest $){ }^{25}$ nulliparity $(\mathrm{HR}=1.42,95 \% \mathrm{Cl} 1.26-1.60),{ }^{26}$ older age at last birth $(0.87 ; 95 \% \mathrm{Cl} 0.85-0.90$; per 5 year increase at last birth $)^{27}$ and earlier-onset of menopause $(\mathrm{HR}=1.89,95 \% \mathrm{Cl} 1.58-2.26)^{28}$ all increase risk of $\mathrm{EC}$, breast feeding $(\mathrm{HR}=0.89,95 \% \mathrm{Cl} 0.81-0.98)^{29}$ and use of the combined oral 
contraceptives $(\mathrm{RR}=0.76,95 \% \mathrm{Cl} 0.73-0.78)^{30}$ decrease risk (Table 1$)$. These risk factors have also been studied in combination with one another, for example nulliparity in combination with menarche at $\geq 13$ years has a null effect $(1.06 ; 95 \% \mathrm{Cl} 0.86-1.32)^{26}$.

All of these factors point to the role of the length of time of endogenous estrogen exposure on EC risk. This notion is however not recent and likely a result of our evolution as elegantly presented by Eaton et al in 1994 in a study of hunter-gatherer societies (data including 19th century Western nations, Japanese and rural Chinese in the 1940s) and contemporary American women to suggest that as women became better fed, their age of menarche decreased. In addition to this earlier menarche, having fewer children and later in life, shorter duration of breastfeeding and later menopause have all impacted on modern women's risk of female cancers including $\mathrm{EC}^{31}$.

\section{Polycystic ovarian syndrome}

Polycystic ovarian syndrome (PCOS) is a common endocrine and metabolic disorder that results in hyperandrogenism, oligo/amenstruation and hirsutism. It is commonly associated with obesity and Type II diabetes. Although many studies have reported that PCOS increases EC risk, most of these did not adjust for $\mathrm{BMI}^{32}$. Based on two case control studies, even when controlling for $\mathrm{BMI}$, there is still an increase in risk $(2.79 ; 95 \% \mathrm{Cl} 1.31-5.96)$, which is higher in premenopausal women $(4.05 ; 95 \% \mathrm{Cl} 2.42-6.76)^{33}$.

The global prevalence of PCOS is $5-10 \%{ }^{34}$, although the challenging diagnostic criteria means that these figures are likely higher. Therefore, a large proportion of the population could potentially benefit from PCOS being included in risk-stratified EC screening strategies. 


\section{Exogenous hormones}

In the 1970s, data became available that women with an intact uterus taking unopposed (oestrogen only) Hormone Replacement Therapy (HRT) were at a 2.3 fold increased risk of EC, rising to 9.5 if taken for $>10$ years. This risk even persisted several years after discontinuation ${ }^{35}$. Combined HRT includes progestogens ('opposed' HRT) and attenuates the proliferating effects of oestrogen on the endometrium and therefore women with an intact uterus are prescribed combination therapy. A 2009 systematic review of 45 studies demonstrated that the risk of EC in women taking combined HRT is not increased ${ }^{36}$, with a $29 \%$ reduction in EC risk reported for those using continuous combined preparations ${ }^{37}$. However, it must be noted that the risk varies based on the type of combined HRT, with a decrease in risk with continuous preparations ( $\mathrm{HR}=0.78,95 \% \mathrm{Cl} 0.72-0.86)$, increase in risk with sequential HRT with progestins given for $<10$ days each month $(\mathrm{HR}=1.76,95 \% \mathrm{Cl} 1.51$ 2.05) but null effect with sequential HRT when progestins given $>10$ days a month ( $H R=1.07$, $95 \% \mathrm{Cl} 0.92-1.04)^{38}$.

\section{Diabetes and cardiovascular disease}

Diabetes and hypertension have been long-established as risk factors for EC. The risk of EC is 40-81\% higher in women with diabetes with overweight/obesity in diabetics possibly explaining some of this association ${ }^{39,40}$. Hypertension increases EC risk independently of $\mathrm{BMI}^{41}$ along with other cardiovascular risk factors (incident hyperglycaemia, total: HDL cholesterol) more recently shown to contribute to this increase in risk ${ }^{42}$.

\section{Tamoxifen}


Tamoxifen is used in both the treatment and prevention of breast cancer. Tamoxifen increases EC risk 2-3 fold, with the increase with longer duration, particularly after 5 years ${ }^{43}$. Data from the National Surgical Adjuvant Breast and Bowel Project P-1 trial reported a doubling in EC risk in women at high risk who were taking tamoxifen as chemoprevention compared with women receiving placebo, with the increased risk primarily in postmenopausal women ${ }^{44}$. Of note, the cancers that occur in tamoxifen-treated women have similar characteristics (stage, grade, histology) to those in the general population and have a good prognosis ${ }^{45}$.

\section{Other lifestyle factors (physical activity, coffee consumption)}

The Women's Health Initiative observational study reported that more time spent sitting was associated with higher levels of unconjugated oestrone, independent of $\mathrm{BMI}^{46}$. Despite the obvious link between the two, weight loss and physical activity may independently affect EC, and so may be potentially two separate risk-reducing strategies ${ }^{47}$. However, such interventions are challenging and difficult to implement. Most recently, a Phase II randomised controlled trial (RCT) of personalised diet and exercise behaviour change in EC patients (Diet and Exercise in Uterine Cancer Survivors, DEUS) ${ }^{48}$ demonstrated that a programme of diet and exercise change in EC patients (up to 3-years post diagnosis) was feasible, with $77 \%$ adherence (20/29). Of the women who declined study participation, convenience was cited as the most common reason ${ }^{49}$. This pilot paves the way for similar interventions in women who would benefit from the risk reduction associated with weight loss and/or increased physical activity. 
There is now strong evidence of a dose-response relationship between coffee consumption ( $\geq 4$ cups a day) and a decrease in EC risk. A proposed mechanism is that coffee increases levels of sex hormone-binding globulin (SHBG), lowering circulating oestrogen levels. The association appears to be particularly strong in obese, postmenopausal women $^{50,51}$.

\section{Genetic and Epigenetic risk factors}

Women at high risk: Women with Lynch Syndrome (LS), previously referred to as Hereditary Nonpolyposis Colorectal Cancer (HNPCC), are at markedly increased risk of EC compared with women in the general population ${ }^{52}$. LS is defined as per the Amsterdam II criteria, used to identify women for genetic testing ${ }^{53}$. LS is caused by a mutation in one of the mismatch repair (MMR) genes MSH2, MLH1, PMS1, PMS2, or MSH6. The cumulative incidence of EC by age 70 (based on a study of 6,350 carriers of pathogenic LS mutations of whom 3,480 female) ranges from $12-47 \%$, with $\mathrm{MSH} 2$ and $\mathrm{MSH} 6$ carriers being at the greatest risk $(46.5 \%$; $95 \% \mathrm{Cl} 38.3-$ 56.3\% and 41.1\%; 95\% $\mathrm{Cl} 28.6-57.9 \%$, respectively) and MLH1 and PMS2 mutation carriers at lower (35.2\%; 95\% $\mathrm{Cl} 28.8-43.4 \%$ and $12.8 \%$; $95 \% \mathrm{Cl}$ 5.2-49.5\%, respectively), but still substantially higher than population-level risk ${ }^{54}$. This risk appears to be directly related to age, with EC usually occurring 15 years earlier than in the low-risk population, with the highest risk between the ages of 55 and 65 years. The risk is substantially lower at age $40(1.9-2.3 \%$ in MLH1, MSH6 and MSH2 carriers) with highest risk (48.9\%) at age 75 in MSH2 carriers $^{54}$.

The Lynch syndrome-associated ECs have a favourable outcome with Møller et al more recently reporting a 10-year crude survival following endometrial, colon or ovarian cancer diagnosis in these women of $80 \%^{55}$. Although most other reports support the 
encouraging survival ${ }^{56}$, there is however some data to suggest that the LS ECs may differ from the sporadic cancers by being more likely to be poorly differentiated, with lymphatic/vascular invasion and diagnosed at advanced stage ${ }^{57}$.

Recent data suggests that BRCA1 mutation carriers may also be at an increased risk of serous EC. In a series of 369 BRCA1/2 carriers (1,779 woman-years follow up) who underwent risk-reducing salpingo-oophorectomy, Saule et al reported a diagnosis of serous EC in two women (SIR 32.2, 95\% Cl 11.5 to $116.4, p<0.001)^{58}$. One potential implication of these preliminary data may be that offering women genetic testing for BRCA1/2, especially those diagnosed with breast cancer in the past, may help detect their predisposition to serous EC, which has a high fatality rate. However, it must be noted that the risk of EC in a BRCA1 carrier is around $3 \%^{58}$ and preventative strategies are not warranted.

These and other advances in knowledge of genetic risk factors have been incorporated into commercial diagnostic panels to be used by those with a family history of EC who 'may benefit from increased surveillance'. These panels test for mutations in a number of genes (including MLH1, MSH2, MSH6, PMS2, PTEN, TP53) but also include those associated with an increased risk of other cancers such as EPCAM, POLD1, BRCA1/2, MUTYH ${ }^{59}$.

Low risk women from the general population: Emerging data from Genome Wide Association Studies (GWAS) is paving the way in our understanding of the genetic component of sporadic EC cases. So far, 20 single nucleotide polymorphisms (SNPs)/low-risk loci (16 directly genotyped SNPs, 11 of the 20 and 6 substitutes) associated with an increased risk of EC (Table 
1) have been described ${ }^{60}$. When taken together, the loci identified to date probably account for $\sim 5 \%$ of endometrial cancer risk ${ }^{61}$.

Epigenetic profiling: HAND2 methylation has been shown to be a common and crucial molecular alteration in EC with a potential to be used as a biomarker for early detection ${ }^{62}$. Moreover, ease of collection of material such as that taken using tampons where epigenetic changes can been detected, given further studies, could be an avenue for a non-invasive screening method. In a study of 146 women with Type I EC sought to detect methylated genes in cervical scrapings, methylation of any two of a panel of 14 genes had a sensitivity of $91.8 \%$ and specificity of $95.5 \%$. The same markers were also detected in a smaller group of women with Type II EC, detecting 13/14 patients ${ }^{63}$. The carcinogenesis mechanism in EC is complex, with suggestion that the familial predisposition may be mediated through epigenetic changes of MMR genes inherited over generations whilst estrogen exerts its effect both on cell proliferation and MMR activity ${ }^{64}$.

Further efforts investigating whether epigenetic signature in cervical material could detect four women's cancers (ovarian, breast, endometrial and cervical) are underway ${ }^{65}$.

Population-level genetic testing for cancer risk is increasingly more widely acceptable and available ${ }^{61}$. It is able to identify those at risk much more efficiently, with fewer resources and increase pick up rate by $50 \%$ compared to family history/clinical criteria alone ${ }^{66}$. Population-based genetic-testing for multiple cancer susceptibility genes will likely lead to implementation studies where the full benefit of such a strategy could be evaluated. As information about EC aetiology accumulates, it may be possible to identify screening and 
prevention interventions that are beneficial to categories of women with specific risk profiles, and risk stratified screening ${ }^{67}$ avenues akin to the efforts in breast and colorectal cancer.

\section{Risk prediction models}

In EC, efforts have focused on building risk prediction models incorporating epidemiological, reproductive and genetic factors, with serum biomarkers, ultrasound features and symptoms included in some. The current advances in these models are discussed below.

Epidemiological factors alone: Several EC risk prediction models have been developed using lifestyle, anthropometric and reproductive factors from large, prospective cohorts. The EPIC (European Prospective Investigation into Cancer and Nutrition) group reported that a risk prediction model which included $\mathrm{BMI}$, reproductive factors (menopausal status, age at menarche, parity, age at first full-term pregnancy and menopause, oral contraceptive use and duration), duration of HRT and smoking status had a discriminative capacity of $77 \%$ (Cstatistic) improving on that based on age alone (71\%) which was significantly better (IDI Index of 0.18) discrimination for predicting 5-year EC risk ${ }^{68}$.

Despite the efforts exploring whether risk factor profile varies between Type I and II EC, data from 14,069 cases and 35,312 controls from the Epidemiology of Endometrial Cancer Consortium suggests that both types share many risk factors ${ }^{10}$, with a greater effect of BMI on Type I when compared for Type II ECs. Of note, similar pattern of risk was reported for high grade endometrioid and Type II cancers. 
Epidemiological factors and ultrasound features: A 2018 systematic review of EC risk prediction and diagnostic models in the general population reported that models including age, reproductive factors, hormone use, BMI, smoking history, comorbidities and endometrial features had a discriminative ability ranging from $0.68-0.77,{ }^{69}$ similar to the models based on the EPIC data ${ }^{68}$.

Epidemiological factors and serum biomarkers: Based on a systematic review of EC riskfactors, Kitson et al have proposed a risk prediction model to incorporate measures of obesity, insulin resistance, unopposed oestrogen exposure and family history, with the latter being based on both epidemiological and biomarker data ${ }^{70}$. The model would stratify general population women into low, medium and high-risk categories and offer prophylactic treatments to reduce EC risk e.g. metformin recommended in those with high insulin resistance score ${ }^{70}$.

Predictive power may be improved by incorporating other biomarkers in the models. Data from EPIC suggests that the best performing markers (adiponectin, estrone, interleukin1 receptor antagonist, tumor necrosis factor-alpha and triglycerides) improved slightly on the discrimination capacity of epi-factor alone model by $1.7 \%{ }^{71}$. Although modest improvements were noted, genetic factors may further improve on the performance of these models.

Epidemiological factors and symptoms: Available since 2012, QCancer uses primary care data to calculate individual risk of any undiagnosed cancer and eleven specific tumour sites (for females), based on epidemiological risk factors and symptoms ${ }^{72,73}$. Although primarily intended for professional use, it also invites patients to use the tool and discuss the results 
with their doctor. For uterine cancer, the Receiver Operator Characteristic (ROC) curve of the model was high at 0.91 , but this was largely attributable to inclusion of $\mathrm{PMB}$ and $\mathrm{BMI}^{74}$ in the tool.

Epidemiological and genetic factors: Efforts to combine genetic data with epidemiological factors to predict cancer risk continue. However, the value of risk-stratified screening for EC will depend on the performance of these models and whether low risk loci provide further discriminatory power. The 2016 Chief Medical Officer's 'Generation Genome' report outlines current risk-stratified approaches in breast, colorectal and prostate cancer ${ }^{67}$ but does not include EC. The latter may have been overlooked due to its known risk factors of obesity and PMB, however in view of longer life expectancy and recently observed increases in fatal EC, there is an impetus to explore screening/risk-stratified approaches further.

\section{Screening strategies}

\section{Screening for EC and impact on mortality}

The main goal of screening is reduction in EC mortality. However, in view of the symptomatic presentation of EC usually detected at an early stage, an impetus to evaluate the impact of screening on EC mortality has been lacking.

\section{Ultrasound}

General population: Transvaginal ultrasound (TVS) is commonly used in the differential diagnosis/investigation of symptomatic women. The thickest antero-posterior diameter of the endometrium (endometrial thickness, ET) is used as an indication of risk of EC and to 
determine whether further and more invasive investigations such as endometrial biopsy are required.

Although TVS may be seen as an intrusive test, data from the ovarian cancer screening trial where women underwent 7-11 annual screens suggests that TVS-based screening in a postmenopausal woman causes very little discomfort (72.7\% reported 'no discomfort') or pain (3.5\% reported 'moderate/severe pain') ${ }^{75}$.

As already discussed, $90 \%$ of women who are diagnosed with EC are symptomatic. In these women, an ET cut-off of $4 \mathrm{~mm}$ has a sensitivity of $98 \%$, with a specificity ranging from $36 \%-68 \%{ }^{76}$. A thickened endometrium is more indicative of Type I EC risk, whereas Type II ECs are more often associated with an atrophied endometrium ${ }^{77}$. Although it is generally accepted that a normal endometrium is less than $4 \mathrm{~mm}$ thick ${ }^{78}$, cut-offs vary dependent on menopausal status (pre-menopausal cut-off dependent on stage in cycle, up to $16 \mathrm{~mm}$; postmenopausal $\sim 4-5 \mathrm{~mm})^{79,80}$ and whether the woman has presented with abnormal bleeding (4-5mm cut-off if symptomatic, $\sim 10 \mathrm{~mm}$ if asymptomatic) ${ }^{79,80}$. The American College of Obstetrics and Gynecology recommends endometrial biopsy in all postmenopausal women with persistent $\mathrm{PMB}$, even where $\mathrm{ET}$ is $\leq 3 \mathrm{~mm}^{79}$. Although Smith-Bindman et al report that in symptomatic postmenopausal women a risk of EC of $\sim 4.6 \%$ in those with ET $\geq 5 \mathrm{~mm}$, similar as in asymptomatic women with $\mathrm{ET} \geq 10 \mathrm{~mm}^{81}$, other studies report the risk to be higher especially in women over 55. Based on the General Practice Research Database data including 2,732 women with uterine cancer (aged $\geq 40$, diagnosed between 2000-2009) and 9537 matched controls (matched on age, sex, practice), Walker et all report positive predictive value (PPV) of $4 \%$ which increases to $9.6 \%(95 \% \mathrm{Cl} 6.2-17.8)$ in those aged over $55 .{ }^{82}$ In pre- 
menopausal women in the general population, screening using TVS is not recommended due to cyclical fluctuations in ET. Similarly, an ET cut-off in HRT users may be higher than $5 \mathrm{~mm}$, some proposing a cut-off of $8 \mathrm{~mm}$ to result in fewer false positives. However, a cautionary note should be made as this would lead to missing detecting true positives in the $5-8 \mathrm{~mm}$ range ${ }^{83}$. There is a paucity of data regarding ET cut-offs and HRT type (sequential vs combined). Initial data on performance of ET as a screening tool for EC at a population level was first reported in a 1999 study of 1,074 postmenopausal women aged 57-61 years undergoing conventional and Doppler TVS using a $4 \mathrm{~mm}$ cut-off ${ }^{84}$. Over a quarter $(27 \%, \mathrm{n}=291)$ of the women underwent endometrial biopsy resulting in 3 cases of EC and 6 cases of AEH being detected. A larger study of 1,926 women was undertaken which was nested within an osteoporosis prevention trial where women underwent TVS at trial entry. Using a $6 \mathrm{~mm}$ cutoff, 42 women underwent endometrial biopsy, with EC diagnosed in one woman, and AEH in 4 85 . A major limitation of this study was that women with an ET of $>6 \mathrm{~mm}$ were excluded from the study, leading to a sampling rate of women with a thickened endometrium of only $45 \%$ (42/92). In 2011, a study based on the data from the ultrasound arm of the United Kingdom Collaborative Trial of Ovarian Cancer Screening (UKCTOCS) where 50,639 of the 202,638 postmenopausal women aged 50-74 were randomised to annual screening using TVS reported the performance of ET as a screening test for EC. Based on 37,038 women with an intact uterus, an ET cut-off of $\geq 5 \mathrm{~mm}$ had a sensitivity of $80.5 \%$ and specificity of $86 \%$ for EC and $A E H$ with 58 investigations per case detected ${ }^{75}$. The sensitivity was lower $(54 \%)$ if a $10 \mathrm{~mm}$ cut-off was chosen (specificity of 95\%) with 17 investigations per case detected. The optimum ET cut-off in this population was $5.15 \mathrm{~mm}$, with a sensitivity of $80.5 \%(95 \% \mathrm{Cl} 72.7-86.8)$ and specificity of $86.2 \%(95 \% \mathrm{Cl} 85.8-86.6)$. Using a logistic regression based on the established epidemiological and reproductive EC risk factors (OCP use, age at menarche, pregnancies 
longer than 6 months, weight, increasing age, personal history of breast and other cancers), women were stratified into quartiles of risk with the highest quartile, containing $39.5 \%$ of the women with EC or AEH in the cohort. In the latter group, a $6.75 \mathrm{~mm}$ ET cut-off achieved a higher sensitivity $(84.3 \%, 95 \% \mathrm{Cl} 71.4-93.0)$ and specificity $(89.9 \%, 95 \% \mathrm{Cl} 89.3-90.5)$ with 22 investigations per case detected ${ }^{75}$.

A 1998 study of 448 healthy postmenopausal low-risk women included screening using both TVS and a concurrent endometrial biopsy. Using a $5 \mathrm{~mm}$ threshold, the sensitivity was $90 \%$, specificity $48 \%$ and the negative predictive value (NPV) $99 \%$. For detecting any abnormality, the PPV was $9 \%$. Based on these values, over half of the women would require investigation, with a low yield (4\%) of endometrial carcinomas ${ }^{86}$. Inclusion of endometrial abnormality detected on TVS has been explored in both UKCTOCS ${ }^{75}$ and a cohort of 9,888 preand perimenopausal women ${ }^{87}$ with some suggestions of the value of including, in addition to ET, any abnormalities noted in the endometrial cavity.

There is currently insufficient evidence to support introducing routine transvaginal ultrasound examination to screen asymptomatic low risk women for $\mathrm{EC}^{88}$.

Women at high risk: With a lifetime risk of developing EC by the age of 80 of up to $43 \%$, various screening strategies have been investigated in women with Lynch Syndrome. The main challenge in using ET as a screening tool in these women is due to a large proportion of women being premenopausal, where ET varies through the menstrual cycle. In a series of 269 LS women undergoing TVS (825.7 women-years of screening), only two cases of EC occurred but neither were detected through screening ${ }^{89}$. In a separate series evaluating annual TVS, of 
the 41 women in the study (totalling 197 women-years) three cases of AEH were detected with the one EC missed as the woman presented with symptoms ${ }^{90}$. This suggests that annual screening using TVS alone does not have a role in screening high-risk women.

\section{Endometrial biopsy}

\section{Endometrial sampling in the general population}

Tissue sampling and subsequent histological examination of the endometrium provides the most accurate diagnosis, however has not been proven to impact on early detection or EC mortality ${ }^{91}$. Dilatation and curettage (D\&C) and Pipelle biopsy are most commonly used, but other commercial samplers are available ${ }^{92}$. These are most commonly used in symptomatic women but have also been explored in high-risk women in a screening context as they are simple, easy to implement in office-based setting and have good performance characteristics (sensitivity $73.5 \%$, specificity $99.4 \%)^{93}$. Limitations across all outpatient endometrial sampling techniques are patient acceptability due to pain and discomfort, and difficulty of access due to presence of cervical stenosis and atrophy, none of which are uncommon or insignificant. The procedure may also result in bleeding, with additional risk of infection, and rarely, uterine perforation. Finally, there is also a recognized sampling error as even with hysteroscopy and endometrial curettage, only $65 \%$ of the endometrial cavity is sampled. Concordance between all histological findings (benign and malignant) from endometrial biopsy compared with hysterectomy is between $60-70 \%{ }^{94}$.

Introduced to the market in 1984 , Pipelle is by far the most studied and commonly used sampling device. Overall, Pipelle samping causes significantly less pain than D\&C, is less time-consuming and cheaper ${ }^{95}$. It has a higher sampling success rate than other aspiration 
devices such as Vabra $(98.7 \% \text { vs } 88.7 \%)^{96}$. However, there are challenges in using each, with the Pipelle still having a $10 \%$ failure rate. Brush cytology methods (similar to cervical brushing/Pap smear) provide an opportunity to sample a greater surface area than the Pipelle or that of outpatient hysteroscopy with endometrial sampling (OHES) therefore reducing inadequate sampling by $25 \%{ }^{97}$. A number of brushes are available, such as the Tao brush, SAP1 device (adequate sample retrieved in 96.3\%, 73\% sensitivity, 95.8\% PPV, 95.3\% NPV), and the more recently described Li brush, which has both high sensitivity $(92.7 \%)$ and specificity $(98.2 \%)^{98}$. Despite the encouraging sensitivity and specificity of Tao Brush, it has a failure rate of $8 \%$ in parous women and $20 \%$ in nulliparous women and is also considerably more and possibly prohibitively expensive in comparison with Pipelle ${ }^{99}$. A study of 439 women of whom 270 provided data on acceptability however reported that the Tao brush was preferred to Pipelle ${ }^{99}$.

There have been no RCTs exploring the impact of a sampling-based screening program on mortality from the disease. A study nested within the Postmenopausal Estrogen/Progestin Interventions Trial including 448 postmenopausal women on estrogen, combined HRT or placebo explored concurrent TVS and sampling. In this study, one EC, 2 AEHs and 8 cases of complex hyperplasia were detected. An ET cut-off of $5 \mathrm{~mm}$ had a sensitivity of $90 \%$, specificity of $48 \%$, PPV of $9 \%$ and NPV of $99 \%$ therefore suggesting that asymptomatic postmenopausal women, TVS with endometrial biopsy has a poor PPV but a high NPV for detecting endometrial disease ${ }^{100}$.

\section{Endometrial sampling in women at high risk}


In view of the poor performance of annual TVS alone in Lynch Syndrome women, endometrial sampling had been explored. In a Finnish Study of 175 women (759 screen years) undergoing TVS and intrauterine biopsy, EC was diagnosed in 14 women, 11 of whom were detected by screening ( 8 by sampling, 4 by TVS). Furthermore, the intrauterine biopsy detected 14 cases of $\mathrm{AEH}^{101}$. A second study of 62 women detected $3 \mathrm{ECs}$, all of which were in women with PMB. The failure rate for the procedure was $8 \%{ }^{102}$. A 2011 systematic review suggested that in surveillance asymptomatic LS women, endometrial sampling should be added to TVS ${ }^{103}$. The performance of OHES versus TVS was reported in a series of 41 LS women who had both tests annually. Although both tests had a similar specificity $(89.8 \%)$, the positive likelihood ratio was higher in $\mathrm{OHES}(9.8,95 \% \mathrm{Cl} 4.6,21)$ with a negative likelihood ratio of 0 suggesting that OHES had a higher diagnostic accuracy for $E C$ and $A E H^{104}$. Women preferences/acceptability have to also be taken into account. A small study of LS women $(n=25)$ reported that TVS causes less discomfort than OHES and that majority would choose TVS over OHES if a single test was required. They however reported similar pain scores for hysteroscopy and Pipelle biopsy ${ }^{105}$. A larger study $(n=370)$ has also shown no statistically significant difference between the two in terms of discomfort and acceptability ${ }^{106}$. For LS women who are at risk of both colon cancer and EC, if the colonoscopy and hysteroscopy (under conscious sedation) are done at the same time, lower pain scores than outpatient hysteroscopy are reported ${ }^{107}$.

A further consideration is cost. In a decision model comparing annual gynaecologic examinations versus annual screening (TVS, endometrial biopsy, CA125) versus hysterectomy with bilateral salpingo-oophorectomy at age 30 in LS women, $48.7 \%, 18.4 \%$ and $0.0060 \%$ were diagnosed with EC, respectively. Surgery led to slightly longer life expectancy (80.0) compared 
to the other two strategies (79.3 years for screening and 77.4 for annual gynecologic examinations) ${ }^{108}$. To prevent EC, 6 prophylactic surgeries need to be performed suggesting risk-reducing hysterectomy may therefore be considered in this group of women. However, in women undergoing surgery the issue of premature menopause needs to be discussed on an individual basis ${ }^{109}$.

\section{Guidance from the professional societies}

The US ${ }^{110}$ and European ${ }^{111}$ professional societies and the Manchester International Consensus Group on Lynch Syndrome Management ${ }^{56}$ have different recommendations as to the best approach to screening/surveillance (Table 2).

The American Cancer Society, unlike most other societies, stratifies the women into average, increased and very high risk of EC (LS women). The recommendation for both average (population risk) and intermediate-risk (defined as those have had increased exposure to unopposed oestrogens, but not those with LS or family history) is for the women to be counselled regarding symptoms and risk of EC at time of menopause.

Low risk: None of the societies advocate screening in low-risk (general population) women.

Intermediate risk: There are cogent reasons to consider screening in the latter group (increased risk but no known LS or other mutation) as women on tamoxifen therapy have a 2-3 fold increase in EC risk. It is worth noting that ET measurement in tamoxifen users presents a challenge due to the tamoxifen-induced sub-epithelial stromal hypertrophy $(>40 \%$ 
of women taking tamoxifen will have an ET of more than $5 \mathrm{~mm}$ ). In addition, several studies have reported a high false positive rate (even when using a 10mm ET cut-off). In a study of 247 women taking tamoxifen matched to 98 controls, Gerber et al identified 52 asymptomatic patients with endometrial thickening who underwent curettage with only one EC diagnosed in this group but 4 uterine perforations reported. Of the 20 symptomatic women, 2 ECs were $\operatorname{diagnosed}^{112}$.

High risk: By current international standards, women defined as being 'high risk' are those who have either LS or a strong family history of EC. Screening guidelines for these women differ slightly between the various professional bodies and societies (Table 2).

The American Cancer Society categorises these women as 'very high risk' and recommends an annual endometrial biopsy from age $35^{110}$. This is similar to the screening recommendations from the Royal College of Obstetrics and Gynaecologists. The American Society of Clinical Oncology (ASCO) and European Society of Medical Oncology (ESMO) guidelines both advise annual TVS and aspiration biopsy screening from age 35 with prophylactic surgery as an option once childbearing is complete ${ }^{111}$. In 2003, The Royal Australian College of Obstetricians and Gynaecologists published a consensus statement suggesting screening is not required, but counselling regarding the risk and prompt investigation of any bleeding is strongly recommended in this group of women ${ }^{113}$.

The timing of both screening and prophylactic approaches for reduction of risk of EC have been refined in the American College of Gastroenterology guidelines which suggest surveillance from age $30-35$ and surgery at age $40-45^{114}$. Risk-reducing surgery is the most 
effective approach in reducing both EC and ovarian cancer risk in women at high risk and is recommended by all professional societies/Manchester International Consensus Group as the primary option to be discussed with the patient. In view of the ovarian cancer risk in these women, the recommended approach is risk-reducing hysterectomy with bilateral salpingooophorectomy. There is encouraging data that compared with screening, such an approach is the most cost-effective and provides greatest gain in quality-adjusted life years ${ }^{115}$.

Asymptomatic women with a family history of LS or colorectal cancer or EC in the family but not as part of Lynch are advised to undergo genetic counselling and testing for MMR gene mutations ${ }^{116}$.

Whilst the focus of this review is screening of asymptomatic women, other recent developments in EC are related to universal screening for LS mutations in all patients with EC at point of diagnosis which is gaining wide support. In unselected EC patients, a 2018 study of 484 patients suggested that universal screening identified $50 \%$ more patients with $\mathrm{LS}^{117}$ who have been missed by current risk assessment tools.

\section{Limitations of screening}

In view of the low specificity and low PPV in the general population, screening is not currently advocated. Major concern in EC screening are the false positive tests which lead to further unnecessary investigations (with estimates of 50 or 100 investigations per case detected) and the additional anxiety in the women. As with any screening strategy, one pertinent issue is that of false negatives. 


\section{Novel screening tests}

The utility of cervical smear tests as a screening tool for endometrial cancer has been explored as far back as $1981^{118}$. In 1,280 asymptomatic women $>45$ years old, cervical cytology was able to detect 8 cases of EC and a further 25 cases of AEH or other atypia. In 2012, Kinde et al detected genetic mutations commonly associated with EC in the Pap smear samples of all women with EC $(24 / 24)^{119}$. Therefore there appears to be opportunity for Pap smear to be used as a method of detecting occult endometrial carcinomas. A PCR-based test (PapSEEK), designed to detect mutations in 18 genes in Pap smear samples detected $81 \%$ of cases from standard Pap smear brush samples and 93\% in Tao brush samples in 382 EC patients. Over three-quarters of the Pap-smear cases were early stage ${ }^{120} .87 .5 \%$ and $37.8 \%$ of women with serous or endometrioid EC respectively will have a cytologically abnormal endometrial cells present at Pap smear ${ }^{121}$. Although not having the necessary performance for use as a screening test at present, it holds promise for detection of the aggressive cancers accounting for highest proportion of EC deaths. However, as cervical smear samples are increasingly being triaged based on being HPV positive, this resource will be lost in all but those who have simultaneous HPV infection.

\section{Targeted screening}

Defining an 'at risk' population based on epidemiological and low to moderate risk genetic factors is likely to be the basis for an EC screening programme if one were to be implemented. In ovarian cancer, based on a combination of epidemiological factors and low risk loci, the risk in the women unselected for family history ranges from $0.35 \%-8.78 \%{ }^{122}$. 
Risk stratified screening would therefore allow classification of women at (1) low risk who would not need screening, (2) intermediate risk who would be offered screening or riskreducing strategies such as intrauterine device with progestogen (e.g. Mirena), which decreases EC risk by $19 \%{ }^{123}$, or (3) high risk (Lynch syndrome $12-47 \%$ lifetime risk) who would be recommended to undergo annual hysteroscopy (and TVS), with hysterectomy advised in those who have completed their families. In addition, women at high risk may be advised to take aspirin as chemoprevention as it has been shown to reduce colorectal cancer risk (CaPP2 trial) $)^{124}$. The effect of different doses $(100 \mathrm{mg}, 300 \mathrm{mg}$ or $600 \mathrm{mg}$ daily) in prevention of a number of cancers including EC is currently being explored in the CaPP3 trial due to report in $2024^{125}$.

There has also been some encouraging preliminary data on metformin, which is thought to reduce cellular proliferation in women with $\mathrm{EC}^{126}$, as a potential chemopreventative agent.

Some of these approaches are dependent on the EC risk based on BMI. In morbidly obese women, in selected women who opt for bariatric surgery for weight loss, the additional advantage of undergoing the procedure is reduction in EC risk.

Progestin-based devices (intrauterine devices such as the Mirena coil) have long been established to have an effect on abrogating endometrial proliferation. In LS women, a trial was planned where women would be randomised to Mirena coil versus control but unfortunately the trial failed to recruit ${ }^{127}$. To ensure adequate protection, biomarkers predicting response to progestin in this context are required. 
Serum based screening as first line test has not been explored. There is however data based on Markov modelling of serum screening using a biomarker panel versus no screening, annual endometrial biopsy or annual TVS which in low risk women aged 50 is not cost effective unless applied to obese women aged $45-80^{128}$. The impetus in screening is to identify non-invasive strategies for screening using biomarkers/panels of promising markers. Sex steroid hormones, LCAM1 and adiponectin may hold promise but the data on latter is based on clinical case series and prognostic studies. Recently a pan-cancer panel (CancerSEEK) ${ }^{129}$ has been described but its value in EC screening is as yet not clear.

Further studies will help to shed some light on both the potential benefits and also longer term harms associated with any of these approaches. Currently encouraging data is only based on small short-term studies.

EC patient engagement is essential in identifying areas to focus on. A 2016 survey of 211 EC patients and their carers highlighted public awareness and development of personalised risk prediction as being two of the most important issues to be addressed ${ }^{130}$. This shows that patients are interested in understanding their own risk and believe that awareness is not adequate at present.

\section{Awareness of presentation and risk factors}

Awareness of EC in the population is low ${ }^{131}$. Increasing awareness of the risk associated with symptomatic presentation and obesity would likely contribute to early detection. A 
systematic review of symptoms reported that up to $90 \%$ of ECs could be diagnosed at an early stage if women experiencing PMB sought medical attention promptly ${ }^{13}$. The NHS health check $^{132}$ is offered to those aged $40-74$ every 5 years via primary care. Assessments take place with a nurse or healthcare assistant and patients are asked questions about their lifestyle and family history, and have height, weight and blood pressure measured. The aim of this is to be able to offer personalised advice to reduce the risk of stroke, heart disease and diabetes. For postmenopausal women, this could be an ideal opportunity to advise women on PMB and EC risk more generally, especially since obesity, hypertension and diabetes are already included in the health check.

The recent Cancer Research UK (CRUK) public awareness campaign includes obesity as one of the major risk factors for cancer. As globally $12 \%$ of the population is obese ${ }^{133}$, expanding on these to highlight the magnitude of EC risk related to obesity may further help raise awareness. As EC arises after menopause, education on the need to promptly present for investigation in case of any bleeding, however slight, is essential. Although an early symptom, PMB is not always assessed as being important by the patient.

Furthermore, awareness of the disease among black women is essential as although the incidence of EC is lower in this group of women, the mortality is higher ${ }^{134}$.

\section{Summary}

Current evidence does not support routine endometrial cancer screening in the general population. The greatest impact may be achieved through education of patients regarding the 
significance of postmenopausal bleeding. Further efforts are needed to focus on detecting the fatal cancers, whether Type I or II.

As most patients with EC present early, it is unlikely, based on the current technology, that a population-based screening program would be instigated. However, in view of the rise in obesity and ageing population, risk stratified approaches based on epidemiological and genetic factors may be of value. This is in line with a 2014 Cochrane review suggesting that in view of the emerging epidemic of EC, it is now time to take action with risk stratification and prevention opportunities fitting well within some of these action plans that merit further exploration ${ }^{135}$

As globally mortality rates are projected to rise in the next 2 decades, there is an impetus to better define risk factors and identify biomarkers that could be used for risk stratification so that preventative strategies such as progestin-based hormonal treatments or screening could be offered.

In high-risk (Lynch Syndrome) women, annual screening with endometrial biopsy and/or TVS are advocated by most societies along with further recommendation for prophylactic surgery on completion of child bearing.

Major efforts over the next few years should be directed towards raising awareness of the disease and exploring risk-stratified screening. 


\section{Acknowledgement}

The authors were supported by the Medical Research Council core funding (MR_UU_12023).

\section{Conflicts of interest}

The authors have no conflicts of interest. 
1. Lortet-Tieulent J, Ferlay J, Bray F, Jemal A. International Patterns and Trends in Endometrial Cancer Incidence, 1978-2013. JNCI: Journal of the National Cancer Institute. 2017;110(4):354361.

2. CRUK. Uterine Cancer Incidence Trends Over Time. 2018; https://www.cancerresearchuk.org/health-professional/cancer-statistics/statistics-bycancer-type/uterine-cancer/incidence\#heading-Two. Accessed 7th June 2019.

3. Sheikh MA, Althouse AD, Freese KE, et al. USA endometrial cancer projections to 2030: should we be concerned? Future oncology. 2014;10(16):2561-2568.

4. Rahib L, Smith BD, Aizenberg R, Rosenzweig AB, Fleshman JM, Matrisian LM. Projecting Cancer Incidence and Deaths to 2030: The Unexpected Burden of Thyroid, Liver, and Pancreas Cancers in the United States. Cancer research. 2014;74(11):2913-2921.

5. Smittenaar CR, Petersen KA, Stewart K, Moitt N. Cancer incidence and mortality projections in the UK until 2035. British journal of cancer. 2016;115(9):1147-1155.

6. Saeaib N, Sriplung H, Pichatechaiyoot A, Bilheem S. Trends in incidence of uterine cancer in Songkhla, Southern Thailand. Journal of gynecologic oncology. 2019;30(2):e22.

7. CRUK. Uterine Cancer Mortality by Age. 2018; https://www.cancerresearchuk.org/healthprofessional/cancer-statistics/statistics-by-cancer-type/uterine-cancer/mortality\#heading-

One.

8. CRUK. Uterine cancer incidence by age. 2019; https://www.cancerresearchuk.org/healthprofessional/cancer-statistics/statistics-by-cancer-type/uterine-cancer/incidence\#headingOne. Accessed 30/07/2019.

9. Sanderson PA, Critchley HO, Williams AR, Arends MJ, Saunders PT. New concepts for an old problem: the diagnosis of endometrial hyperplasia. Human reproduction update. 2017;23(2):232-254.

10. Setiawan VW, Yang HP, Pike MC, et al. Type I and II endometrial cancers: have they different risk factors? Journal of clinical oncology : official journal of the American Society of Clinical Oncology. 2013;31(20):2607-2618.

11. Talhouk A, McAlpine JN. New classification of endometrial cancers: the development and potential applications of genomic-based classification in research and clinical care. Gynecologic Oncology Research and Practice. 2016;3(1):14.

12. CRUK. Uterine Cancer Survival by Stage at Diagnosis. 2016; https://www.cancerresearchuk.org/health-professional/cancer-statistics/statistics-bycancer-type/uterine-cancer/survival\#heading-Three. Accessed 7th June 2019.

13. Clarke MA, Long BJ, Del Mar Morillo A, Arbyn M, Bakkum-Gamez JN, Wentzensen N. Association of Endometrial Cancer Risk With Postmenopausal Bleeding in Women: A Systematic Review and Meta-analysis. JAMA internal medicine. 2018;178(9):1210-1222.

14. Gerber B, Krause A, Muller H, et al. Ultrasonographic detection of asymptomatic endometrial cancer in postmenopausal patients offers no prognostic advantage over symptomatic disease discovered by uterine bleeding. European journal of cancer. 2001;37(1):64-71.

15. Bourdel N, Chauvet P, Tognazza E, Pereira B, Botchorishvili R, Canis M. Sampling in Atypical Endometrial Hyperplasia: Which Method Results in the Lowest Underestimation of Endometrial Cancer? A Systematic Review and Meta-analysis. J Minim Invasive Gynecol. 2016;23(5):692-701.

16. CRUK. Lifetime Risk of Uterine Cancer. 2018; https://www.cancerresearchuk.org/healthprofessional/cancer-statistics/statistics-by-cancer-type/uterine-cancer/risk-factors\#headingZero. Accessed 10th June 2019.

17. Allen NE, Key TJ, Dossus L, et al. Endogenous sex hormones and endometrial cancer risk in women in the European Prospective Investigation into Cancer and Nutrition (EPIC). Endocrinerelated cancer. 2008;15(2):485-497. 
18. Brown KF, Rumgay $\mathrm{H}$, Dunlop $\mathrm{C}$, et al. The fraction of cancer attributable to modifiable risk factors in England, Wales, Scotland, Northern Ireland, and the United Kingdom in 2015. British journal of cancer. 2018;118(8):1130-1141.

19. Aune D, Navarro Rosenblatt DA, Chan DS, et al. Anthropometric factors and endometrial cancer risk: a systematic review and dose-response meta-analysis of prospective studies. Annals of oncology : official journal of the European Society for Medical Oncology / ESMO. 2015;26(8):1635-1648.

20. Jenabi $E$, Poorolajal J. The effect of body mass index on endometrial cancer: a meta-analysis. Public health. 2015;129(7):872-880.

21. Mackintosh ML, Crosbie EJ. Obesity-driven endometrial cancer: is weight loss the answer? BJOG : an international journal of obstetrics and gynaecology. 2013;120(7):791-794.

22. Adams TD, Stroup AM, Gress RE, et al. Cancer incidence and mortality after gastric bypass surgery. Obesity. 2009;17(4):796-802.

23. Upala S, Anawin S. Bariatric surgery and risk of postoperative endometrial cancer: a systematic review and meta-analysis. Surg Obes Relat Dis. 2015;11(4):949-955.

24. MacKintosh ML, Derbyshire AE, McVey RJ, et al. The impact of obesity and bariatric surgery on circulating and tissue biomarkers of endometrial cancer risk. International journal of cancer Journal international du cancer. 2019;144(3):641-650.

25. Gong TT, Wang YL, Ma XX. Age at menarche and endometrial cancer risk: a dose-response meta-analysis of prospective studies. Scientific reports. 2015;5:14051.

26. Schonfeld SJ, Hartge P, Pfeiffer RM, et al. An aggregated analysis of hormonal factors and endometrial cancer risk by parity. Cancer. 2013;119(7):1393-1401.

27. Setiawan VW, Pike MC, Karageorgi S, et al. Age at last birth in relation to risk of endometrial cancer: pooled analysis in the epidemiology of endometrial cancer consortium. American journal of epidemiology. 2012;176(4):269-278.

28. Wu Y, Sun W, Liu H, Zhang D. Age at Menopause and Risk of Developing Endometrial Cancer: A Meta-Analysis. BioMed research international. 2019;2019:8584130.

29. Jordan SJ, Na R, Johnatty SE, et al. Breastfeeding and Endometrial Cancer Risk: An Analysis From the Epidemiology of Endometrial Cancer Consortium. Obstet Gynecol. 2017;129(6):1059-1067.

30. Collaborative Group on Epidemiological Studies on Endometrial C. Endometrial cancer and oral contraceptives: an individual participant meta-analysis of 27276 women with endometrial cancer from 36 epidemiological studies. The lancet oncology. 2015;16(9):10611070.

31. Eaton SB, Pike MC, Short RV, et al. Women's reproductive cancers in evolutionary context. The Quarterly review of biology. 1994;69(3):353-367.

32. Harris HR, Terry KL. Polycystic ovary syndrome and risk of endometrial, ovarian, and breast cancer: a systematic review. Fertility research and practice. 2016;2:14.

33. Barry JA, Azizia MM, Hardiman PJ. Risk of endometrial, ovarian and breast cancer in women with polycystic ovary syndrome: a systematic review and meta-analysis. Human reproduction update. 2014;20(5):748-758.

34. Ding T, Hardiman PJ, Petersen I, Wang F-F, Qu F, Baio G. The prevalence of polycystic ovary syndrome in reproductive-aged women of different ethnicity: a systematic review and metaanalysis. Oncotarget. 2017;8(56):96351-96358.

35. Grady D, Gebretsadik T, Kerlikowske K, Ernster V, Petitti D. Hormone replacement therapy and endometrial cancer risk: a meta-analysis. Obstet Gynecol. 1995;85(2):304-313.

36. Furness S, Roberts H, Marjoribanks J, Lethaby A, Hickey M, Farquhar C. Hormone therapy in postmenopausal women and risk of endometrial hyperplasia. The Cochrane database of systematic reviews. 2009(2):Cd000402.

37. Beral V, Bull D, Reeves G. Endometrial cancer and hormone-replacement therapy in the Million Women Study. Lancet. 2005;365(9470):1543-1551. 
38. Brinton LA, Felix AS. Menopausal hormone therapy and risk of endometrial cancer. The Journal of steroid biochemistry and molecular biology. 2014;142:83-89.

39. Starup-Linde J, Karlstad O, Eriksen SA, et al. CARING (CAncer Risk and INsulin analoGues): the association of diabetes mellitus and cancer risk with focus on possible determinants - a systematic review and a meta-analysis. Current drug safety. 2013;8(5):296-332.

40. Zhang ZH, Su PY, Hao JH, Sun YH. The role of preexisting diabetes mellitus on incidence and mortality of endometrial cancer: a meta-analysis of prospective cohort studies. International journal of gynecological cancer : official journal of the International Gynecological Cancer Society. 2013;23(2):294-303.

41. Aune D, Sen A, Vatten L. Hypertension and the risk of endometrial cancer: a systematic review and meta-analysis of case-control and cohort studies. Scientific reports. 2017;7:44808-44808.

42. Kitson SJ, Lindsay J, Sivalingam VN, et al. The unrecognized burden of cardiovascular risk factors in women newly diagnosed with endometrial cancer: A prospective case control study. Gynecologic oncology. 2018;148(1):154-160.

43. ACOG. Tamoxifen and Uterine Cancer. 2014; https://www.acog.org/Clinical-Guidance-andPublications/Committee-Opinions/Committee-on-Gynecologic-Practice/Tamoxifen-andUterine-Cancer?IsMobileSet=false. Accessed 15/08/2019.

44. Fisher B, Costantino JP, Wickerham DL, et al. Tamoxifen for prevention of breast cancer: report of the National Surgical Adjuvant Breast and Bowel Project P-1 Study. Journal of the National Cancer Institute. 1998;90(18):1371-1388.

45. Barakat RR, Gilewski TA, Almadrones L, et al. Effect of adjuvant tamoxifen on the endometrium in women with breast cancer: a prospective study using office endometrial biopsy. Journal of clinical oncology : official journal of the American Society of Clinical Oncology. 2000;18(20):3459-3463.

46. Oh $\mathrm{H}$, Arem $\mathrm{H}$, Matthews $\mathrm{CE}$, et al. Sitting, physical activity, and serum oestrogen metabolism in postmenopausal women: the Women's Health Initiative Observational Study. British journal of cancer. 2017;117(7):1070-1078.

47. Schmid D, Behrens G, Keimling M, Jochem C, Ricci C, Leitzmann M. A systematic review and meta-analysis of physical activity and endometrial cancer risk. European journal of epidemiology. 2015;30(5):397-412.

48. Koutoukidis DA, Beeken RJ, Manchanda R, Burnell M, Knobf MT, Lanceley A. Diet and exercise in uterine cancer survivors (DEUS pilot) - piloting a healthy eating and physical activity program: study protocol for a randomized controlled trial. Trials. 2016;17(1):130.

49. Koutoukidis DA, Beeken RJ, Manchanda R, et al. Recruitment, adherence, and retention of endometrial cancer survivors in a behavioural lifestyle programme: the Diet and Exercise in Uterine Cancer Survivors (DEUS) parallel randomised pilot trial. BMJ open. 2017;7(10):e018015.

50. Lafranconi A, Micek A, Galvano F, et al. Coffee Decreases the Risk of Endometrial Cancer: A Dose-Response Meta-Analysis of Prospective Cohort Studies. Nutrients. 2017;9(11).

51. Lukic M, Guha N, Licaj I, et al. Coffee Drinking and the Risk of Endometrial Cancer: An Updated Meta-Analysis of Observational Studies. Nutrition and cancer. 2018;70(4):513-528.

52. Lindor NM, Petersen GM, Hadley DW, et al. Recommendations for the care of individuals with an inherited predisposition to Lynch syndrome: a systematic review. JAMA : the journal of the American Medical Association. 2006;296(12):1507-1517.

53. Vasen HF, Watson P, Mecklin JP, Lynch HT. New clinical criteria for hereditary nonpolyposis colorectal cancer (HNPCC, Lynch syndrome) proposed by the International Collaborative group on HNPCC. Gastroenterology. 1999;116(6):1453-1456.

54. Dominguez-Valentin M, Sampson JR, Seppälä $T$, et al. Cancer risks by gene, age, and gender in 6350 carriers of pathogenic mismatch repair variants: findings from the Prospective Lynch Syndrome Database. Genetics in Medicine. 2019. 
55. Moller P, Seppala T, Bernstein I, et al. Cancer incidence and survival in Lynch syndrome patients receiving colonoscopic and gynaecological surveillance: first report from the prospective Lynch syndrome database. Gut. 2017;66(3):464-472.

56. Crosbie EJ, Ryan NAJ, Arends MJ, et al. The Manchester International Consensus Group recommendations for the management of gynecological cancers in Lynch syndrome. Genetics in medicine : official journal of the American College of Medical Genetics. 2019;21(10):23902400.

57. Broaddus RR, Lynch HT, Chen LM, et al. Pathologic features of endometrial carcinoma associated with HNPCC: a comparison with sporadic endometrial carcinoma. Cancer. 2006;106(1):87-94.

58. Saule C, Mouret-Fourme E, Briaux A, et al. Risk of Serous Endometrial Carcinoma in Women With Pathogenic BRCA1/2 Variant After Risk-Reducing Salpingo-Oophorectomy. Journal of the National Cancer Institute. 2018;110(2).

59. Invitae. Hereditary endometrial 2019; https://www.invitae.com/en/patients/conditions/PC000004/. Accessed 06/08/2019.

60. Bafligil C, Thompson, D. J., Smith, M. J., Lophatananon, A., Ryan, N., Naqvi, A., Evans, D. G., Crosbie, E. Constructing a Panel of Common Predisposition Variants to Predict Women That Are at High-Risk of Developing Endometrial Cancer. 2019(Reproductive Sciences, Supplement 1, Volume 26):p. 339A-339A.

61. Spurdle $A B$, Bowman MA, Shamsani J, Kirk J. Endometrial cancer gene panels: clinical diagnostic vs research germline DNA testing. Modern Pathology. 2017;30:1048.

62. Jones $A$, Teschendorff $A E$, $L i ~ Q$, et al. Role of DNA Methylation and Epigenetic Silencing of HAND2 in Endometrial Cancer Development. PLoS medicine. 2013;10(11):e1001551.

63. Huang RL, Su PH, Liao YP, et al. Integrated Epigenomics Analysis Reveals a DNA Methylation Panel for Endometrial Cancer Detection Using Cervical Scrapings. Clinical cancer research : an official journal of the American Association for Cancer Research. 2017;23(1):263-272.

64. Banno K, Yanokura M, lida M, Masuda K, Aoki D. Carcinogenic mechanisms of endometrial cancer: involvement of genetics and epigenetics. The journal of obstetrics and gynaecology research. 2014;40(8):1957-1967.

65. FORECEE. FORECEE (Female Cancer Prediction Using Cervical Omics to Individualise Screening and Prevention). https://forecee.eu/. Accessed 15/08/2019.

66. Manchanda R, Gaba F. Population Based Testing for Primary Prevention: A Systematic Review. Cancers (Basel). 2018;10(11):424.

67. Department of Health. Annual Report of the Chief Medical Officer 2016: Generation Genome. 2016;

https://www.gov.uk/government/uploads/system/uploads/attachment data/file/631043/C MO annual report generation genome.pdf.

68. Husing A, Dossus L, Ferrari $P$, et al. An epidemiological model for prediction of endometrial cancer risk in Europe. European journal of epidemiology. 2016;31(1):51-60.

69. Alblas M, Velt KB, Pashayan N, Widschwendter M, Steyerberg EW, Vergouwe Y. Prediction models for endometrial cancer for the general population or symptomatic women: $A$ systematic review. Critical reviews in oncology/hematology. 2018;126:92-99.

70. Kitson SJ, Evans DG, Crosbie EJ. Identifying High-Risk Women for Endometrial Cancer Prevention Strategies: Proposal of an Endometrial Cancer Risk Prediction Model. Cancer prevention research. 2017;10(1):1-13.

71. Fortner RT, Husing A, Kuhn T, et al. Endometrial cancer risk prediction including serum-based biomarkers: results from the EPIC cohort. International journal of cancer Journal international du cancer. 2017;140(6):1317-1323.

72. ClinRisk. QCancer. 2017; https://www.qcancer.org/female/. Accessed 24/06/2019.

73. Shapley M, Mansell G, Jordan JL, Jordan KP. Positive predictive values of $>/=5 \%$ in primary care for cancer: systematic review. Br J Gen Pract. 2010;60(578):e366-377. 
74. Hippisley-Cox J, Coupland C. Symptoms and risk factors to identify women with suspected cancer in primary care: derivation and validation of an algorithm. $\mathrm{Br} J$ Gen Pract. 2013;63(606):e11-21.

75. Jacobs I, Gentry-Maharaj A, Burnell M, et al. Sensitivity of transvaginal ultrasound screening for endometrial cancer in postmenopausal women: a case-control study within the UKCTOCS cohort. The lancet oncology. 2011;12(1):38-48.

76. Masciullo V, Amadio G, Lo Russo D, Raimondo I, Giordano A, Scambia G. Controversies in the management of endometrial cancer. Obstet Gynecol Int. 2010;2010:638165.

77. Felix AS, Weissfeld JL, Stone RA, et al. Factors associated with Type I and Type II endometrial cancer. Cancer causes \& control : CCC. 2010;21(11):1851-1856.

78. Matteson KA, Robison K, Jacoby VL. Opportunities for Early Detection of Endometrial Cancer in Women With Postmenopausal Bleeding. JAMA internal medicine. 2018;178(9):1222-1223.

79. Gynecologists TACoOa. ACOG Committee Opinion on Gynecologic Practice. 2018; 734:https://www.acog.org/Clinical-Guidance-and-Publications/Committee-

Opinions/Committee-on-Gynecologic-Practice/The-Role-of-Transvaginal-Ultrasonography-inEvaluating-the-Endometrium-of-Women-With-Postmenopausal?IsMobileSet=false. Accessed 19/11/2019.

80. Radiographers TSCo. Guidelines For Professional Ultrasound Practice. In:2019.

81. Smith-Bindman R, Weiss E, Feldstein V. How thick is too thick? When endometrial thickness should prompt biopsy in postmenopausal women without vaginal bleeding. Ultrasound in obstetrics \& gynecology : the official journal of the International Society of Ultrasound in Obstetrics and Gynecology. 2004;24(5):558-565.

82. Walker $\mathrm{S}$, Hyde $\mathrm{C}$, Hamilton W. Risk of uterine cancer in symptomatic women in primary care: case-control study using electronic records. Br J Gen Pract. 2013;63(614):e643-648.

83. Winter TC, 3rd. Endometrial Thickness in Symptomatic Postmenopausal Patients Receiving Hormone Replacement Therapy or Tamoxifen. Radiographics : a review publication of the Radiological Society of North America, Inc. 2018;38(2):658-659.

84. Vuento MH, Pirhonen JP, Makinen JI, et al. Screening for endometrial cancer in asymptomatic postmenopausal women with conventional and colour Doppler sonography. British journal of obstetrics and gynaecology. 1999;106(1):14-20.

85. Fleischer AC, Wheeler JE, Lindsay I, et al. An assessment of the value of ultrasonographic screening for endometrial disease in postmenopausal women without symptoms. American journal of obstetrics and gynecology. 2001;184(2):70-75.

86. Smith-Bindman R, Kerlikowske K, Feldstein VA, et al. Endovaginal ultrasound to exclude endometrial cancer and other endometrial abnormalities. JAMA : the journal of the American Medical Association. 1998;280(17):1510-1517.

87. Kim MJ, Kim JJ, Kim SM. Endometrial evaluation with transvaginal ultrasonography for the screening of endometrial hyperplasia or cancer in premenopausal and perimenopausal women. Obstet Gynecol Sci. 2016;59(3):192-200.

88. Sundar S, Balega J, Crosbie E, et al. BGCS uterine cancer guidelines: Recommendations for practice. European journal of obstetrics, gynecology, and reproductive biology. 2017;213:7197.

89. Dove-Edwin I, Boks D, Goff S, et al. The outcome of endometrial carcinoma surveillance by ultrasound scan in women at risk of hereditary nonpolyposis colorectal carcinoma and familial colorectal carcinoma. Cancer. 2002;94(6):1708-1712.

90. Rijcken FE, Mourits MJ, Kleibeuker JH, Hollema H, van der Zee AG. Gynecologic screening in hereditary nonpolyposis colorectal cancer. Gynecologic oncology. 2003;91(1):74-80.

91. National Cancer Institute. Endometrial Cancer Screening (PDQ $\left.{ }^{\circledR}\right)$ : Patient Version. 2019; https://www.cancer.gov/types/uterine/patient/endometrial-screening-pdq. Accessed 02/08/2019. 
92. Du J, Li Y, Lv S, et al. Endometrial sampling devices for early diagnosis of endometrial lesions. Journal of cancer research and clinical oncology. 2016;142(12):2515-2522.

93. Clark TJ, Voit D, Gupta JK, Hyde C, Song F, Khan KS. Accuracy of hysteroscopy in the diagnosis of endometrial cancer and hyperplasia: a systematic quantitative review. JAMA : the journal of the American Medical Association. 2002;288(13):1610-1621.

94. Demirkiran F, Yavuz E, Erenel H, Bese T, Arvas M, Sanioglu C. Which is the best technique for endometrial sampling? Aspiration (pipelle) versus dilatation and curettage (D\&C). Archives of gynecology and obstetrics. 2012;286(5):1277-1282.

95. Rauf R, Shaheen A, Sadia S, et al. Outpatient endometrial biopsy with Pipelle vs diagnostic dilatation and curettage. J Ayub Med Coll Abbottabad. 2014;26(2):145-148.

96. Rodriguez GC, Yaqub N, King ME. A comparison of the Pipelle device and the Vabra aspirator as measured by endometrial denudation in hysterectomy specimens: the Pipelle device samples significantly less of the endometrial surface than the Vabra aspirator. American journal of obstetrics and gynecology. 1993;168(1 Pt 1):55-59.

97. Bagaria M, Shields E, Bakkum-Gamez JN. Novel approaches to early detection of endometrial cancer. Current opinion in obstetrics \& gynecology. 2017;29(1):40-46.

98. Han L, Du J, Zhao L, et al. An Efficacious Endometrial Sampler for Screening Endometrial Cancer. Frontiers in oncology. 2019;9(67).

99. Williams AR, Brechin S, Porter AJ, Warner P, Critchley HO. Factors affecting adequacy of Pipelle and Tao Brush endometrial sampling. BJOG : an international journal of obstetrics and gynaecology. 2008;115(8):1028-1036.

100. Langer RD, Pierce JJ, O'Hanlan KA, et al. Transvaginal ultrasonography compared with endometrial biopsy for the detection of endometrial disease. Postmenopausal Estrogen/Progestin Interventions Trial. The New England journal of medicine. 1997;337(25):1792-1798.

101. Renkonen-Sinisalo L, Butzow R, Leminen A, Lehtovirta P, Mecklin JP, Jarvinen HJ. Surveillance for endometrial cancer in hereditary nonpolyposis colorectal cancer syndrome. International journal of cancer Journal international du cancer. 2007;120(4):821-824.

102. Lecuru F, Le Frere Belda MA, Bats AS, et al. Performance of office hysteroscopy and endometrial biopsy for detecting endometrial disease in women at risk of human nonpolyposis colon cancer: a prospective study. International journal of gynecological cancer : official journal of the International Gynecological Cancer Society. 2008;18(6):1326-1331.

103. Auranen A, Joutsiniemi T. A systematic review of gynecological cancer surveillance in women belonging to hereditary nonpolyposis colorectal cancer (Lynch syndrome) families. Acta obstetricia et gynecologica Scandinavica. 2011;90(5):437-444.

104. Manchanda R, Saridogan E, Abdelraheim A, et al. Annual outpatient hysteroscopy and endometrial sampling (OHES) in HNPCC/Lynch syndrome (LS). Archives of gynecology and obstetrics. 2012;286(6):1555-1562.

105. Elmasry K, Davies AJ, Evans DG, Seif MN, Reynolds K. Strategies for endometrial screening in the Lynch syndrome population: a patient acceptability study. Familial cancer. 2009;8(4):431439.

106. Bain C, Parkin DE, Cooper KG. Is outpatient diagnostic hysteroscopy more useful than endometrial biopsy alone for the investigation of abnormal uterine bleeding in unselected premenopausal women? A randomised comparison. BJOG : an international journal of obstetrics and gynaecology. 2002;109(7):805-811.

107. Huang M, Sun C, Boyd-Rogers S, et al. Prospective study of combined colon and endometrial cancer screening in women with lynch syndrome: a patient-centered approach. Journal of oncology practice. 2011;7(1):43-47.

108. Chen LM, Yang KY, Little SE, Cheung MK, Caughey AB. Gynecologic cancer prevention in Lynch syndrome/hereditary nonpolyposis colorectal cancer families. Obstet Gynecol. 2007;110(1):18-25. 
109. Moldovan R, Keating S, Clancy T. The impact of risk-reducing gynaecological surgery in premenopausal women at high risk of endometrial and ovarian cancer due to Lynch syndrome. Familial cancer. 2015;14(1):51-60.

110. Smith RA, Andrews KS, Brooks D, et al. Cancer screening in the United States, 2019: A review of current American Cancer Society guidelines and current issues in cancer screening. CA: $a$ cancer journal for clinicians. 2019;69(3):184-210.

111. Stoffel EM, Mangu PB, Gruber SB, et al. Hereditary colorectal cancer syndromes: American Society of Clinical Oncology Clinical Practice Guideline endorsement of the familial riskcolorectal cancer: European Society for Medical Oncology Clinical Practice Guidelines. Journal of clinical oncology : official journal of the American Society of Clinical Oncology. 2015;33(2):209-217.

112. Gerber B, Krause A, Muller $\mathrm{H}$, et al. Effects of adjuvant tamoxifen on the endometrium in postmenopausal women with breast cancer: a prospective long-term study using transvaginal ultrasound. Journal of clinical oncology : official journal of the American Society of Clinical Oncology. 2000;18(20):3464-3470.

113. Robertson G. Screening for endometrial cancer. The Medical journal of Australia. 2003;178(12):657-659.

114. Syngal S, Brand RE, Church JM, Giardiello FM, Hampel HL, Burt RW. ACG clinical guideline: Genetic testing and management of hereditary gastrointestinal cancer syndromes. The American journal of gastroenterology. 2015;110(2):223-262; quiz 263.

115. Kwon JS, Sun CC, Peterson SK, et al. Cost-effectiveness analysis of prevention strategies for gynecologic cancers in Lynch syndrome. Cancer. 2008;113(2):326-335.

116. Bohiltea RE, Ancar V, Cirstoiu MM, Radoi V, Bohiltea LC, Furtunescu F. Project for the National Program of Early Diagnosis of Endometrial Cancer Part I. J Med Life. 2015;8(3):305-314.

117. Adar T, Rodgers LH, Shannon KM, et al. Universal screening of both endometrial and colon cancers increases the detection of Lynch syndrome. Cancer. 2018;124(15):3145-3153.

118. Koss LG, Schreiber K, Oberlander SG, Moukhtar M, Levine HS, Moussouris HF. Screening of asymptomatic women for endometrial cancer. $C A$ : a cancer journal for clinicians. 1981;31(5):300-317.

119. Kinde I, Bettegowda C, Wang Y, et al. Evaluation of DNA from the Papanicolaou test to detect ovarian and endometrial cancers. Science translational medicine. 2013;5(167):167ra164.

120. Gusberg SB, Milano C. Detection of endometrial cancer and its precursors. Cancer. 1981;47(5 Suppl):1173-1175.

121. Roelofsen T, Geels YP, Pijnenborg JM, et al. Cervical cytology in serous and endometrioid endometrial cancer. International journal of gynecological pathology : official journal of the International Society of Gynecological Pathologists. 2013;32(4):390-398.

122. Pearce CL, Stram DO, Ness RB, et al. Population distribution of lifetime risk of ovarian cancer in the United States. Cancer epidemiology, biomarkers \& prevention : a publication of the American Association for Cancer Research, cosponsored by the American Society of Preventive Oncology. 2015;24(4):671-676.

123. Felix AS, Gaudet MM, La Vecchia C, et al. Intrauterine devices and endometrial cancer risk: a pooled analysis of the Epidemiology of Endometrial Cancer Consortium. International journal of cancer Journal international du cancer. 2015;136(5):E410-422.

124. Burn J, Gerdes AM, Macrae F, et al. Long-term effect of aspirin on cancer risk in carriers of hereditary colorectal cancer: an analysis from the CAPP2 randomised controlled trial. Lancet. 2011;378(9809):2081-2087.

125. CaPP3. Cancer Prevention Programme (CaPP3). https://www.cancerresearchuk.org/aboutcancer/find-a-clinical-trial/a-trial-looking-at-different-doses-of-aspirin-to-prevent-cancer-inpeople-with-lynch-syndrome-capp3\#undefined. Accessed 15/08/2019.

126. Sivalingam V. The role of metformin in obesity-driven endometrial cancer (PhD thesis) [PhD], University of Manchester; 2016. 
127. POET. A trial looking at a way of preventing cancer of the womb lining (endometrial cancer) (POET). https://www.cancerresearchuk.org/about-cancer/find-a-clinical-trial/a-trial-lookingat-a-way-of-preventing-cancer-of-the-womb-lining\#undefined. Accessed 15/08/2019.

128. Havrilesky LJ, Maxwell GL, Myers ER. Cost-effectiveness analysis of annual screening strategies for endometrial cancer. American journal of obstetrics and gynecology. 2009;200(6):640 e641648.

129. Cohen JD, Li L, Wang Y, et al. Detection and localization of surgically resectable cancers with a multi-analyte blood test. Science. 2018;359(6378):926-930.

130. Wan YL, Beverley-Stevenson R, Carlisle D, et al. Working together to shape the endometrial cancer research agenda: The top ten unanswered research questions. Gynecologic oncology. 2016;143(2):287-293.

131. Ackermann S, Renner SP, Fasching PA, Poehls U, Bender HG, Beckmann MW. Awareness of general and personal risk factors for uterine cancer among healthy women. European journal of cancer prevention : the official journal of the European Cancer Prevention Organisation. 2005;14(6):519-524.

132. NHS. NHS Health Check. https://www.nhs.uk/conditions/nhs-health-check/. Accessed 07/08/2019.

133. Collaborators GBDO, Afshin A, Forouzanfar $\mathrm{MH}$, et al. Health Effects of Overweight and Obesity in 195 Countries over 25 Years. The New England journal of medicine. 2017;377(1):1327.

134. Barrett RJ, 2nd, Harlan LC, Wesley MN, et al. Endometrial cancer: stage at diagnosis and associated factors in black and white patients. American journal of obstetrics and gynecology. 1995;173(2):414-422; discussion 422-413.

135. Crosbie E, Morrison J. The emerging epidemic of endometrial cancer: Time to take action. The Cochrane database of systematic reviews. 2014(12):Ed000095.

136. Crosbie EJ, Zwahlen M, Kitchener HC, Egger M, Renehan AG. Body mass index, hormone replacement therapy, and endometrial cancer risk: a meta-analysis. Cancer epidemiology, biomarkers \& prevention : a publication of the American Association for Cancer Research, cosponsored by the American Society of Preventive Oncology. 2010;19(12):3119-3130.

137. Neill AS, Nagle CM, Protani MM, Obermair A, Spurdle AB, Webb PM. Aspirin, nonsteroidal anti-inflammatory drugs, paracetamol and risk of endometrial cancer: a case-control study, systematic review and meta-analysis. International journal of cancer Journal international du cancer. 2013;132(5):1146-1155.

138. Cheng TH, Thompson DJ, O'Mara TA, et al. Five endometrial cancer risk loci identified through genome-wide association analysis. Nature genetics. 2016;48(6):667-674.

139. Long J, Zheng W, Xiang YB, et al. Genome-wide association study identifies a possible susceptibility locus for endometrial cancer. Cancer epidemiology, biomarkers \& prevention : $a$ publication of the American Association for Cancer Research, cosponsored by the American Society of Preventive Oncology. 2012;21(6):980-987.

140. Spurdle AB, Thompson DJ, Ahmed S, et al. Genome-wide association study identifies a common variant associated with risk of endometrial cancer. Nature genetics. 2011;43(5):451454.

141. De Vivo I, Prescott J, Setiawan VW, et al. Genome-wide association study of endometrial cancer in E2C2. Human genetics. 2014;133(2):211-224.

142. Cheng TH, Thompson D, Painter J, et al. Meta-analysis of genome-wide association studies identifies common susceptibility polymorphisms for colorectal and endometrial cancer near SH2B3 and TSHZ1. Scientific reports. 2015;5:17369.

143. Thompson DJ, O'Mara TA, Glubb DM, et al. CYP19A1 fine-mapping and Mendelian randomization: estradiol is causal for endometrial cancer. Endocrine-related cancer. 2016;23(2):77-91. 
144. CRUK. Womb cancer: Screening. 2017; https://www.cancerresearchuk.org/aboutcancer/womb-cancer/getting-diagnosed/screening. Accessed 23/08/2019.

145. Colombo N, Creutzberg C, Amant F, et al. ESMO-ESGO-ESTRO Consensus Conference on Endometrial Cancer: diagnosis, treatment and follow-up. Annals of oncology : official journal of the European Society for Medical Oncology / ESMO. 2016;27(1):16-41. 


\section{Table legends}

Table 1: Epidemiological, reproductive and genetic risk factors for endometrial cancer

Table 2: Professional Societies Screening Guidelines 
Table 1: Epidemiological, reproductive and genetic risk factors for endometrial cancer

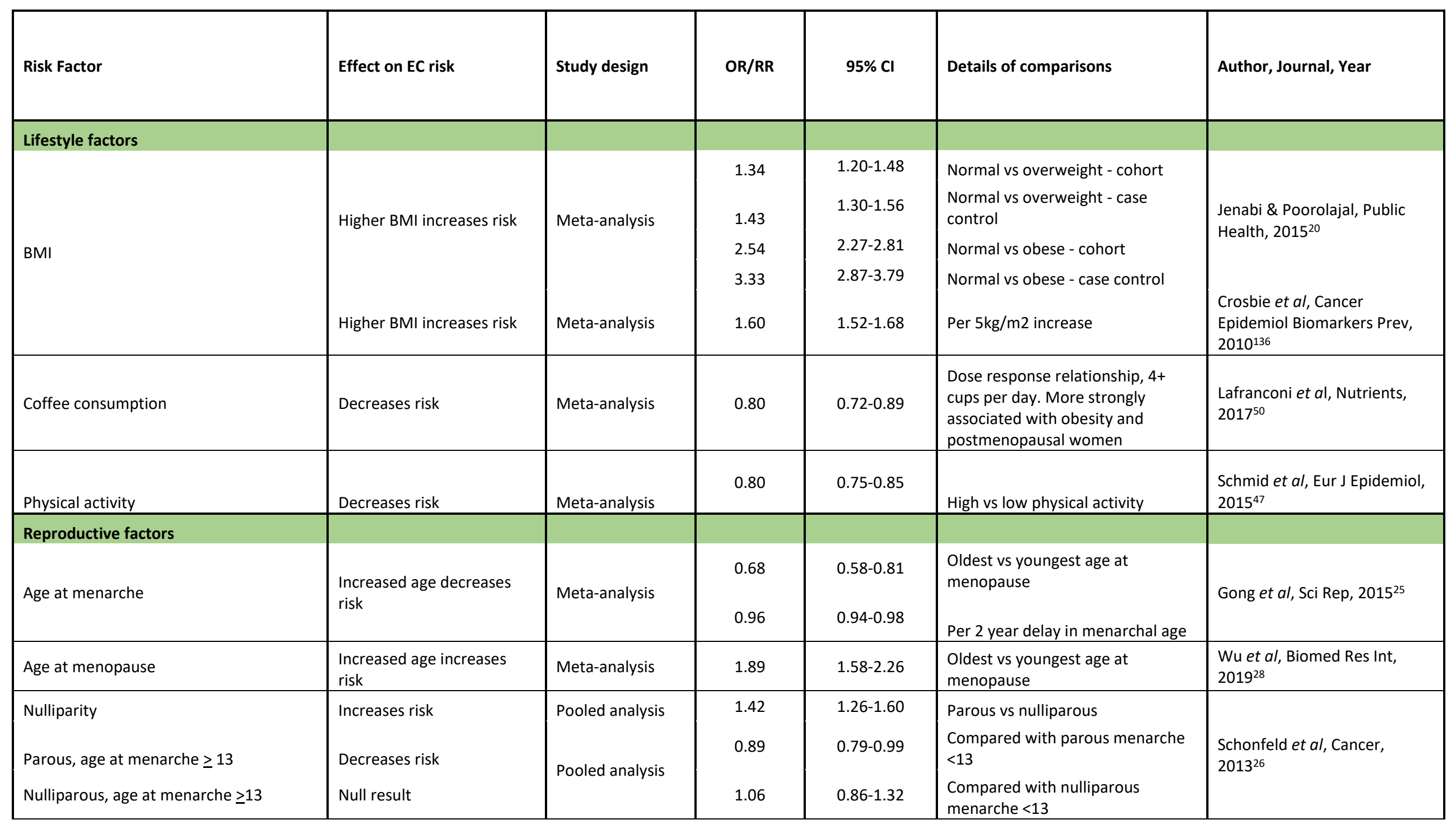




\begin{tabular}{|c|c|c|c|c|c|c|}
\hline Breast feeding & Decreases risk & Meta-analysis & 0.89 & $0.81-0.98$ & $\begin{array}{l}\text { Ever breastfeeding vs none. } \\
\text { Longer duration associated with } \\
\text { lower risk, but levels off beyond } 6 \text { - } \\
\text { 9months. No difference seen by } \\
\text { breastfeeding. }\end{array}$ & $\begin{array}{l}\text { Jordan et al, Obstet Gynecol, } \\
2017^{29}\end{array}$ \\
\hline Age at last birth & Younger age increases risk & & 0.87 & $0.85-0.90$ & Per 5 year increase at last birth & $\begin{array}{l}\text { Setiawan et al, Am J } \\
\text { Epidemiol, } 2012^{27}\end{array}$ \\
\hline $\begin{array}{l}\text { Endogenous oestrogen level } \\
\text { Estrone } \\
\text { Estradiol } \\
\text { Free estradiol }\end{array}$ & High level = higher risk & $\begin{array}{l}\text { Prospective case- } \\
\text { control study of } \\
247 \text { Ecs and } 481 \\
\text { controls }\end{array}$ & $\begin{array}{l}2.66 \\
2.07 \\
1.66 \\
\end{array}$ & $\begin{array}{l}1.50-4.72 \\
1.20-3.60 \\
0.98-2.82 \\
\end{array}$ & Lowest tertile vs highest tertile & $\begin{array}{l}\text { Allen et al, Endocr Relat } \\
\text { Cancer, } 2008^{17}\end{array}$ \\
\hline \multicolumn{7}{|l|}{ Exogenous hormones } \\
\hline OCP use (combined) & Decreases risk & Meta-analysis & 0.76 & $0.73-0.78$ & Per every 5 years of use & $\begin{array}{l}\text { Collaborative Group on } \\
\text { Epidemiological Studies of } \\
\text { Endometrial Cancer, Lancet, } \\
2008^{30}\end{array}$ \\
\hline \multicolumn{7}{|l|}{ HRT use } \\
\hline Oestrogen only & Increases risk & Meta-analysis & $\begin{array}{l}2.3 \\
9.5\end{array}$ & & $\begin{array}{l}\text { Users vs nonusers } \\
\text { Used for } 10 \text { years or more }\end{array}$ & $\begin{array}{l}\text { Grady et al, Obstet Gynecol, } \\
1995^{35}\end{array}$ \\
\hline Oestrogen/progesterone continuous & Decreases risk & Meta-analysis & 0.78 & $0.72-0.86$ & Ever use vs never use & \\
\hline Sequential HRT $<10$ days per month & Increases risk & Meta-analysis & 1.76 & $1.51-2.05$ & Ever use vs never use & Biochem Mol Biol, 2014 ${ }^{38}$ \\
\hline Sequential HRT $\geq 10$ days per month & Neutral & Meta-analysis & 1.07 & $0.92-1.04$ & Ever use vs never use & \\
\hline \multicolumn{7}{|l|}{ Medicines } \\
\hline Aspirin & Decreases risk & $\begin{array}{l}\text { Case control } \\
\text { study of } 1398 \\
\text { cases, } 740 \\
\text { controls }\end{array}$ & $\begin{array}{l}0.54 \\
0.87\end{array}$ & $\begin{array}{l}0.38-0.78 \\
0.79-0.96\end{array}$ & $\begin{array}{l}\text { At least } 2 \text { aspirin per week } \\
\text { Ever vs never use }\end{array}$ & Neil et al, Int J Cancer, $2013^{137}$ \\
\hline Tamoxifen use & Increases risk & Prevention trial & 2.53 & $1.35-4.97$ & $\begin{array}{l}\text { In women at increased risk of } \\
\text { breast cancer }\end{array}$ & $\begin{array}{l}\text { Fisher et al, J Natl Cancer Inst, } \\
1998^{44}\end{array}$ \\
\hline Gynaecological conditions & & & & & & \\
\hline
\end{tabular}




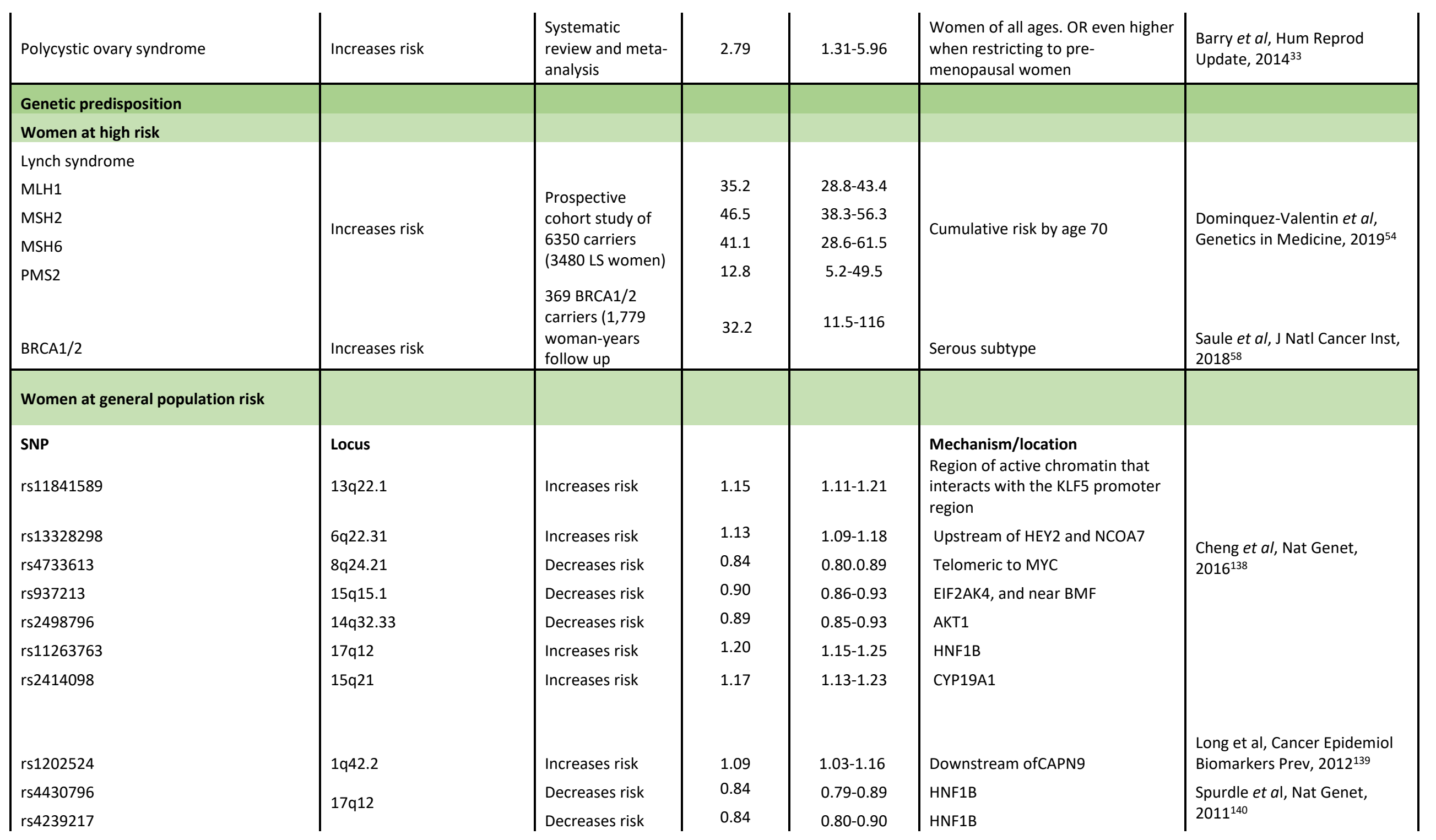




\begin{tabular}{|c|c|c|c|c|c|c|}
\hline rs7501939 & & Decreases risk & 0.86 & $0.82-0.91$ & HNF1B & \\
\hline rs9459805 & $\operatorname{chr} 6$ & & 1.19 & $1.10-1.29$ & RNASET locus & $\begin{array}{l}\text { De Vivo et al, Hum Genet, } \\
2014^{141}\end{array}$ \\
\hline rs3184504 & $12 \mathrm{q} 24$ & & 1.1 & $1.07-1.13$ & $\begin{array}{l}\text { Missense variant in the SH2B3 } \\
\text { gene }\end{array}$ & Cheng et al, Sci Rep, $2015^{142}$ \\
\hline $\begin{array}{l}\text { rs12970291 } \\
\text { rs727479 }\end{array}$ & chr 15 & $\begin{array}{l}\text { Increased risk, } \\
\text { most strongly } \\
\text { associated with } \\
\text { circulating E2 }\end{array}$ & 1.15 & $\begin{array}{r}1.11-1 / 38 \\
1.11-1.21\end{array}$ & $\begin{array}{l}\text { Near the TSHZ1 gene } \\
\text { CYP19A1 }\end{array}$ & $\begin{array}{l}\text { Thompson et al, Endocr Relat } \\
\text { Cancer, } 2016^{143}\end{array}$ \\
\hline
\end{tabular}

Footnote: $B M I=$ Body Mass Index; OCP=Oral Contraceptive Pill; HRT=Hormone Replacement Therapy 
Table 2: Professional Societies Screening Guidelines

\begin{tabular}{|c|c|c|c|c|c|c|}
\hline \multirow[b]{2}{*}{ Risk } & \multirow[b]{2}{*}{ Definition } & \multicolumn{4}{|c|}{ Mode of screening/prevention } & \multirow[b]{2}{*}{ Society } \\
\hline & & $\begin{array}{l}\text { No screening } \\
\text { Advise to visit GP/family } \\
\text { physician if experience } \\
\text { PMB, advise of increased } \\
\text { risk after the menopause }\end{array}$ & $\begin{array}{c}\text { Annual endometrial } \\
\text { biopsy from age } 35\end{array}$ & $\begin{array}{l}\text { Annual TVS } \\
\text { from age } 35\end{array}$ & $\begin{array}{c}\text { Hysterectomy } \\
\text { (with salpingo- } \\
\text { oophorectomy*) } \\
\text { from age } 40\end{array}$ & \\
\hline \multirow{2}{*}{ Average risk } & \multirow{2}{*}{ Population level, $3 \%$} & \multirow{2}{*}{$\checkmark$} & & & & $\mathrm{ACS}^{110}$ \\
\hline & & & & & & $\mathrm{BGCS}^{88} ; \mathrm{CRUK}^{144}$ \\
\hline \multirow{3}{*}{$\begin{array}{l}\text { Intermediate } \\
\text { risk** }\end{array}$} & \multirow{3}{*}{$\begin{array}{l}\uparrow \text { unopposed oestrogens, } \\
\text { no family history (<10\% risk) }\end{array}$} & \multirow{3}{*}{$\checkmark$} & & & & $\mathrm{ACS}^{110}$ \\
\hline & & & & & & $\mathrm{BGCS}^{88} ; \mathrm{CRUK}^{144}$ \\
\hline & & & & & & $\begin{array}{l}\text { ESMO-ESGO- } \\
\text { ESTRO }^{145}\end{array}$ \\
\hline \multirow{2}{*}{ High risk } & \multirow{2}{*}{$\begin{array}{l}\text { Lynch Syndrome (LS) or } \\
\text { family history (>10\% risk) }\end{array}$} & & $\checkmark$ & & & $\mathrm{ACS}^{110}$ \\
\hline & & & $\checkmark$ & $\checkmark$ & & $\mathrm{BGCS}^{88} ; \mathrm{CRUK}^{144}$ \\
\hline
\end{tabular}

Footnote: TVS=transvaginal ultrasound; PMB=postmenopausal bleeding; * to reduce ovarian cancer risk; ** (As per ACS criteria): history of unopposed estrogen therapy, late menopause, tamoxifen therapy, nulliparity, infertility or failure to ovulate, obesity, diabetes or hypertension; ACS=American Cancer Society;BGCS=British Gynaecological Cancer Society; CRUK=Cancer Research UK; ESGO=European Society of Gynaecological Oncology; ESMO=European Society of Medical Oncology; ESTRO=European SocieTy for Radiotherapy \& Oncology 